\title{
KNOWLEDGE OF PATIENTS WITH TYPE 2 DIABETES MELLITUS ABOUT THEIR CONDITIION - A DESCRIPTIIVE ANALYSIS
}

\section{Wijesinghe $\mathrm{MK}^{1}$, Liyanarachchi $\mathrm{KD}^{2}$, Somasundaram $\mathrm{NP}^{2}$}

${ }^{1}$ Faculty of medicine, University of Birmingham,United Kindom. ${ }^{2}$ Diabetes and Endocrine Unit, National Hospital of Sri Lanka.

\begin{abstract}
Patients' knowledge about diabetes is a vital aspect of diabetes self-management. A descriptive, cross-sectional study was conducted in Colombo, Sri Lanka, to assess the knowledge of diabetes among patients with type 2 diabetes mellitus using self-administered questionnaires. Patients' educational status, their awareness on symptoms of dysglycaemia and complications of diabetes as well as their knowledge on preventive strategies of diabetic complications were assessed. The results revealed that $70.6 \%$ of the 279 participants had a good or a very good overall knowledge about their condition and the complications associated with diabetes. However, significant gaps in knowledge were seen in the patients' awareness of hypoglycaemic symptoms and symptoms of diabetic neuropathy. Furthermore, patients with a poor education and patients with a low socioeconomic status were found to have a poorer knowledge of diabetes.
\end{abstract}

\section{INTRODUCTION}

Type 2 diabetes mellitus is a state of hyperglycaemia, which results from a combination of the body's inability to make efficient use of insulin (insulin resistance) and inadequate insulin production from beta cells (1). Globally, 347 million people are suffering from diabetes and $90 \%$ of them have type 2 diabetes $(2,3)$. Type 2 diabetes is most prevalent in people of South Asian origin, where it is six times more common compared to people of Caucasian origin (4). Rapidly increasing prevalence of type 2 diabetes as a result of rise in obesity, increase in sedentary lifestyles, an ageing population and urbanization is a global concern (5). Sri Lanka is a developing country with rapid urbanization, which is experiencing increased incidence of 'Western diseases' such as obesity and diabetes. The epidemiological data has shown an increase in prevalence of diabetes in Sri Lanka has increased from $2.5 \%$ in 1990 to $14.2 \%$ in males and $13.5 \%$ in females by the year $2005(7,8)$.

Diabetes mellitus is the cause for 4 million annual deaths worldwide (9) and over $80 \%$ of these deaths take place in low-income and middle-income countries (10). The high rate of mortality and morbidity of the disease is associated with its macrovascular and microvascular complications (11) and these long-term consequences can be prevented with better management of diabetes. Managing blood pressure, blood lipid levels, smoking cessation, stopping alcohol, increasing physical activity and adhering to a healthy diet are the key components in managing this condition in order prevent these complications and self-management is highlighted as a crucial component of diabetes care (12).

Poor patient knowledge about their condition as act as a major barrier to obtaining optimal self-management skills (13) and it is important that patients understand and retain key information such as the necessary lifestyle modifications in order to improve their health. A previous study, conducted in Pakistan, to assess the knowledge of diabetes among patients with diabetes revealed that only $13.6 \%$ of the participants had a good knowledge about diabetes (14). A similar study conducted at Moratuwa, Sri Lanka, showed that more than $90 \%$ of the participants were unable to recognize hyperglycaemic and hypoglycaemic symptoms, $42 \%$ of the participants didn't know the target blood glucose level and more than $50 \%$ of the participants didn't believe annual follow-ups were needed to manage their condition (15). $90 \%$ of the participants in this study were female and they lived in a specific geographical area and generalizability of the study findings was debatable. Our study aims to assess the knowledge of type 2 diabetes mellitus among a larger sample of patients with type 2 diabetes from different geographical areas of Colombo, attending the outpatient clinic of a well-known tertiary referral centre in the capital of Sri Lanka, Colombo.

\section{METHODS}

A descriptive, cross-sectional study was conducted in the diabetes outpatient clinic in a tertiary hospital in Colombo, Sri Lanka. It is the leading government sector referral centre in Sri Lanka for endocrinology and diabetes.

A sample size of 257 participants was calculated using the following equation:

$$
\text { Sample size }=\frac{Z_{1-a / 2^{2}} p(1-p)}{d^{2}}
$$

$\mathrm{Z}_{1-\mathrm{a} / 2}$ is the standard normal variant. $\mathrm{Z}_{1-\mathrm{a} / 2}$ was assumed to be 1.96 given that the significant $\mathrm{p}$ value is less than $0.05 . \mathrm{p}$ is the prevalence of unsatisfactory knowledge based on our pilot study, which is $21.2 \%$. d is equal to 
absolute error, which is 5\%. However, 279 participants were included in our study.

This study was conducted after the ethical approval from the ethics review committee of National hospital of Sri Lanka. The aims of the study were explained thoroughly to all participants and verbal consent was obtained prior to the recruitment for the study. A random cohort of patients attending the diabetes clinic between the $8^{\text {th }}$ of May to $8^{\text {h }}$ of June 2015 who were above 18 years of age and were diagnosed at least 3 months ago were selected for the study. Patients with poor vision and those with an inability to read or write were excluded from the study. Pre-tested, anonymous, self-administered questionnaires (in 3 languages; Sinhalese, Tamil and English) were issued to assess their knowledge on diabetes, its management, its complications and its preventative measures. The questionnaire contained 16 questions, in which, 10 questions were on demographics and 10 questions were regarding the knowledge on diabetes.

The statistical analysis was carried out using Statistical Package for the Social Sciences (PASW Statistics version 18.0.0).

\section{RESULTS}

The mean age of the study sample was 56.17 (SD of 12.52), ranging from 18 to 85 years. $72.4 \%$ were males and $83.3 \%$ were married. Only a small proportion of the participants $(26 \%)$ had completed school and majority of the participants were unemployed $(67.8 \%)$. The study sample had an almost equal proportion of patients with low and high family incomes. Rest of the demographic and clinical details are summarized in table 1.

The total mean knowledge score of the participants was $73.06 \%$ (SD $=2.82)$. Most of the patients $(60.6 \%)$ had a very good score $(>75 \%)$ regarding the knowledge on diabetes. However, significant gaps in knowledge were seen in patients' awareness of hypoglycaemic symptoms, general knowledge about diabetes, neuropathic symptoms and prevention of neuropathic complications. Only 49.1\% of the patients correctly identified a hypoglycaemic attack. Almost half of the participants $(47 \%)$ believed that diabetes could be cured and only 29\% knew the different types of diabetes. Furthermore, $41.2 \%$ of participants were unaware of the correct frequency of meals to obtain. Many patients also had a poor ability to recognize neuropathic symptoms and take preventative measures to avert foot ulcers (Table 2, Table 3, Figure 1).

The overall knowledge score about diabetes increased significantly with the level of education $(p=0.001)$. This shows that patients with a high level of education have a greater degree of knowledge about type 2 diabetes and vice versa (Figure 2). Moreover, there was a significant increase in the mean knowledge score of patients with their socioeconomic status $(\mathrm{p}=0.03)$. Patients with a low income $(<10,000$ rupees per month) had lower knowledge score compared to patients with a high income and monthly family income of 5000-10000 rupees scored the lowest knowledge score (Figure 3). Duration of diabetes also had a directly proportionate relationship with the knowledge scores. However, this relationship was not statistically significant $(p=0.104)$.

\section{Table 1: Demographic profile of the study group of patients with diabetes attending a tertiary hospital in Colombo}

\begin{tabular}{|c|c|}
\hline Demographic variables & $\begin{array}{l}\text { Percentage of } \\
\text { participants }\end{array}$ \\
\hline \multicolumn{2}{|l|}{ Sex } \\
\hline Male & $72.4 \%$ \\
\hline Female & $27.6 \%$ \\
\hline \multicolumn{2}{|l|}{ Relationship status } \\
\hline Single & $4.4 \%$ \\
\hline Married & $83.3 \%$ \\
\hline Separated & $0.7 \%$ \\
\hline Divorced & $1.8 \%$ \\
\hline Widowed & $9.5 \%$ \\
\hline \multicolumn{2}{|l|}{ Province } \\
\hline Colombo & $81.5 \%$ \\
\hline Other & $18.5 \%$ \\
\hline \multicolumn{2}{|l|}{ Education level } \\
\hline Illiterate & $4.7 \%$ \\
\hline Incomplete schooling & $12.1 \%$ \\
\hline $\mathrm{O} / \mathrm{L}$ & $57.1 \%$ \\
\hline $\mathrm{A} / \mathrm{L}$ & $22.7 \%$ \\
\hline University & $2.6 \%$ \\
\hline $\mathrm{PhD}$ & $0.7 \%$ \\
\hline \multicolumn{2}{|l|}{ Employment status } \\
\hline Employed & $32.2 \%$ \\
\hline Unemployed & $67.8 \%$ \\
\hline \multicolumn{2}{|l|}{ Monthly family income(RS) } \\
\hline$<5000$ & $17.1 \%$ \\
\hline $5000-10000$ & $25.5 \%$ \\
\hline $10000-25000$ & $31.5 \%$ \\
\hline$>25000$ & $23.5 \%$ \\
\hline \multicolumn{2}{|l|}{ Home environment } \\
\hline Living with family & $92 \%$ \\
\hline Living with others & $0.7 \%$ \\
\hline Living alone & $0.4 \%$ \\
\hline \multicolumn{2}{|l|}{ Clinical data } \\
\hline \multicolumn{2}{|l|}{ Duration of diabetes } \\
\hline$<5$ years & $36.1 \%$ \\
\hline $5-10$ years & $21.0 \%$ \\
\hline$>10$ years & $42.9 \%$ \\
\hline \multicolumn{2}{|l|}{ Treatment modality } \\
\hline Lifestyle modifications & $2.6 \%$ \\
\hline $\begin{array}{l}\text { Oral anti- hyperglycaemic } \\
\text { medication }\end{array}$ & $63.9 \%$ \\
\hline Insulin alone & $13.5 \%$ \\
\hline $\begin{array}{l}\text { Insulin+anti-hyperglycaemic } \\
\text { medication }\end{array}$ & $20.1 \%$ \\
\hline
\end{tabular}

Patients had good knowledge in areas such as the awareness of hyperglycaemic symptoms, disease management and benefits of lifestyle modifications (exercise, smoking, weight loss) and they also had a good knowledge of renal and cardiovascular complications and preventative measures required to overcome ocular complications. 


\begin{tabular}{|c|c|}
\hline Question & $\begin{array}{l}\text { Percentage of } \\
\text { correct } \\
\text { responses }(\%)\end{array}$ \\
\hline Know that diabetes cannot be cured & 53 \\
\hline Know the common types of diabetes & 29 \\
\hline Know that diabetes can be inherited & 76.3 \\
\hline Awareness of hyperglycemic symptoms & 80.3 \\
\hline Awareness of hypoglycemic symptoms & 49.1 \\
\hline $\begin{array}{l}\text { Know the management of hyperglycemic } \\
\text { attack }\end{array}$ & 73.5 \\
\hline $\begin{array}{l}\text { Know the management of hypoglycemic } \\
\text { attack }\end{array}$ & 72 \\
\hline Know the benefits of weight loss & 93.9 \\
\hline Know the harmfulness of smoking & 90 \\
\hline Know the benefits of exercise & 95 \\
\hline Know the frequency of meals & 58.8 \\
\hline Know the renal complications & 94.6 \\
\hline Know the cardiovascular complications & 89.6 \\
\hline $\begin{array}{l}\text { Know the symptoms of neuropathic } \\
\text { complications }\end{array}$ & 48.4 \\
\hline $\begin{array}{l}\text { Know the preventative measures for } \\
\text { ocular complications }\end{array}$ & 91.8 \\
\hline $\begin{array}{l}\text { Know the preventative measures for foot } \\
\text { ulcers }\end{array}$ & 67.7 \\
\hline
\end{tabular}

\section{DISCUSSION}

It is an obvious fact that the knowledge regarding the disease and its' self-management are very important in order to achieve the optimum control in chronic diseases such as diabetes. Evidence suggests that poor patient knowledge about diabetes is associated with poor glycaemic control leading complications such as diabetic retinopathy (16). Our study demonstrated that the knowledge regarding their disease among patients with diabetes is good. Majority had a good understanding regarding the disease, the importance of diet and exercises in order to control diabetes and the possible complications such as cardiovascular events, nephropathy and retinopathy. However, their knowledge regarding hypoglycaemia, neuropathy and foot ulcer prevention is poor and a reasonable percentage of patients believed that diabetes could be cured. Level of education in our community had a direct relationship with the good knowledge of disease and its' self-management.
Table 3 and Figure 1: Categorized knowledge scores of the participants ${ }^{15}$

\begin{tabular}{ccc}
\hline Knowledge score $(\%)$ & Grade & $\begin{array}{c}\% \text { of } \\
\text { participants }\end{array}$ \\
\hline$>=75$ & Very good & $60.6 \%$ \\
$65-74$ & Good & $10 \%$ \\
$50-64$ & Average & $20.8 \%$ \\
$40-49$ & Poor & $3.9 \%$ \\
$<40$ & Very poor & $4.7 \%$ \\
\hline
\end{tabular}

Figure 1:

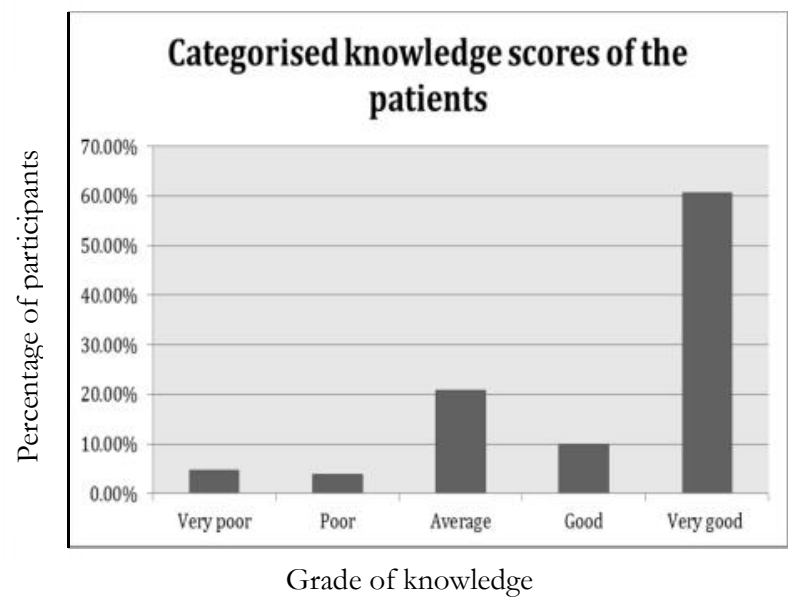

\section{Figure 2: The correlation between the level of education and mean knowledge score}

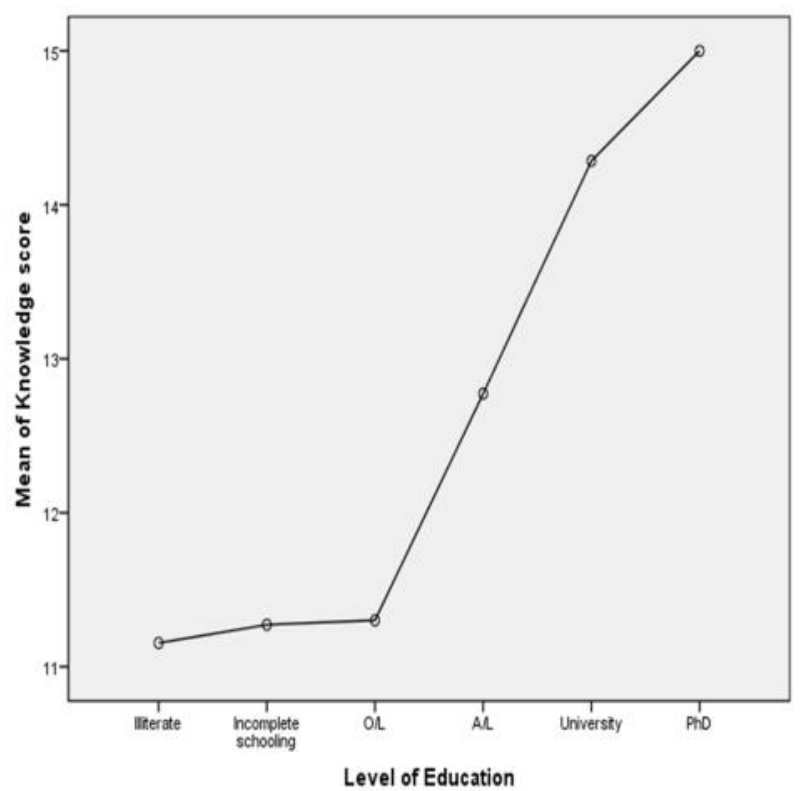

The overall knowledge score of the patients with diabetes is adequate. Previous studies done in Sri Lanka (15), Pakistan (14) and Singapore (17) have shown knowledge 
Figure 3: The correlation between mean knowledge score and monthly family income

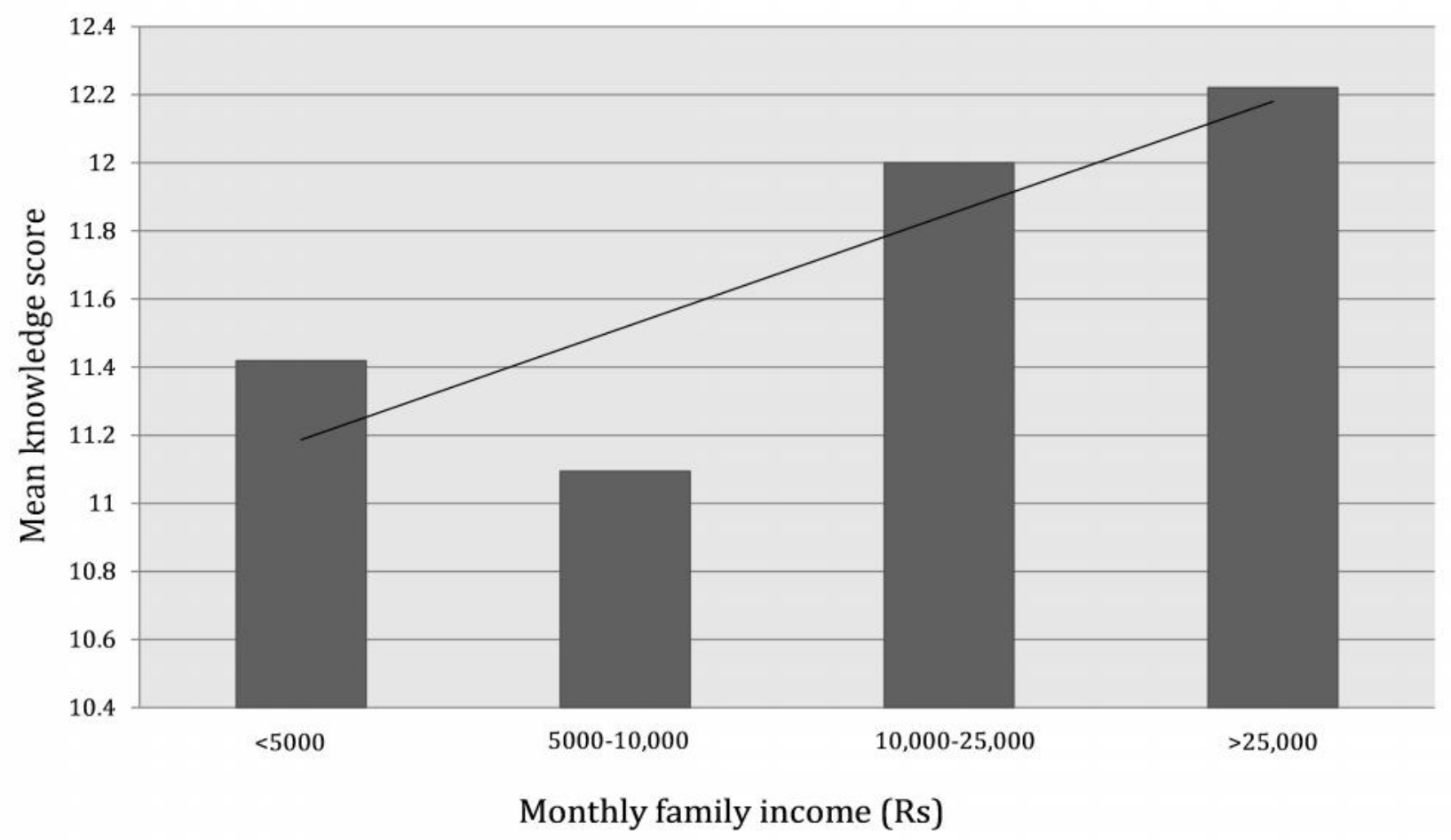

score of $68 \%, 13.6 \%$ and $66.1 \%$ respectively. Our study population had an overall knowledge score of $73 \%$, which is encouraging. The level of education showed direct relationship with the overall knowledge score of the patients. Higher literacy levels comparable to developed countries that we have achieved in our patients may be the reason for better results in our patient population.

This study shows robust evidence to exhibit that majority of the participants has a good or very good level of knowledge about type 2 diabetes mellitus. Nevertheless, the participants showed to have a poor understanding in certain facts about diabetes and its self-management, especially with diabetic neuropathy and the prevention of foot problems. Therefore, these identified areas of weak knowledge should be addressed in future educational programs. Empowering patients with adequate knowledge about all the aspects of diabetes will improve diabetes self-management and reduce its' complications.

Reasonable percentage of patients throughout the world still believes that Type 2 diabetes can be cured. Previous studies done in Sri Lanka (15), India (18) and Singapore (17) have demonstrated that $44 \%, 62 \%$ and $25 \%$ of the patients in respective countries believed that diabetes is curable ${ }^{8}$. This study also demonstrated a similar percentage of patients $(47 \%)$ who believes that diabetes can be cured and take treatment hoping for a cure.

Our study had a well representative study sample in terms of socio-economic status and range of ages. However, there were several drawbacks in our study. Some patients with severe, untreated ocular complications were unable to take part in the study due to visual difficulties.
Illiterate participants $(4.2 \%)$ required the assistance of their family members in order to fill out self-administered questionnaires. This affected the uniformity of the method of data collection, which in turn would affect the study results. The lack of a standardized method to involve illiterate participants also acted as a drawback of this study. The fact that the majority of our study sample was males and most of the participants living in Colombo province also question the generalizability of our results to the entire Sri Lankan population.

\section{CONCLUSIONS}

The Sri Lankan population of diabetes had a good overall knowledge about diabetes and it is related to the level of education. However, there are knowledge gaps especially related to awareness of hpoglycaemic symptoms, symptoms of neuropathy and avoiding foot problems. Interestingly, patients with a lower level of education and lower family income had a lower degree of knowledge about diabetes. These findings can be utilized to devise an integrated education program to empower patients with the necessary knowledge about diabetes. The study also identified particular high-risk groups of patients to be targeted. Therefore, clinicians can be advised to be more proactive with such patients and ensure that they gain the required knowledge regarding diabetes.

\section{REFERENCES}

1. World Health Organisation (WHO). Diabetes Fact Sheet [internet]. 2014[cited 2015 Jan 04]. Available from URL 
http://www.who.int/mediacentre/factsheets/fs312/ en/

2. Danaei G, Finucane MM, Lu Y, Singh GM, Cowan MJ, Paciorek CJ, Lin JK et al. National, regional, and global trends in fasting plasma glucose and diabetes prevalence since 1980: systematic analysis of health examination surveys and epidemiological studies with 370 countryyears and 2.7 million participants. Lancet. 2011; 378(9785): 31-40.

3. Definition, diagnosis and classification of diabetes mellitus and its complications. Part 1: Diagnosis and classification of diabetes mellitus. Geneva, World Health Organization, 1999.

4. Nazroo JY. The Health of Britain's Ethnic Minorities: Findings From a National Survey. London, England: Policy Studies Institute; 1997.

5. Wild S, Roglic G, Green A, Sicree R, King H. Global Prevalence of Diabetes Estimates for the year 2000 and projections for 2030. Diabetes Care. 2004; 27(5): 10471053.

6. Katulanda P, Sheriff MH, Matthews DR. The diabetes epidemic in Sri Lanka-growing problem. Ceylon Medical Journal. 2006; 51(1): 26-28.

7. Illangasekera U, Nugegoda DB, Perera LS. Prevalence of diabetes mellitus and impaired glucose tolerance in a rural Sri Lankan community. Ceylon Medical Journal. 1993; 38: 123-126.

8. Wijewardena K, Mohideen MR, Mendis S, Fernando DS, Kulathilaka T, Weerasekara D et al. Prevalence of hypertension, diabetes and obesity: baseline findings of a population based survey in four provinces in Sri Lanka. Ceylon Medical Journal. 2005; 50: 62-70.

9. International Diabetes Federation. Diabetes roadmap for the un high level summit on non-communicable diseases (NCDs) [internet] 2011[cited 2015 January 05]. Available from URL: www.idf.org/webdata/Diabetesroadmap.pdf

10. Mathers CD, Loncar D. Projections of global mortality and burden of disease from 2002 to 2030. Public Library of Science Medicine. 2006; 3(11): e442.

11. American Diabetes Association. Implications of the United Kingdom prospective diabetes study. Diabetes Care. 2003; 26(1): S28-S32.

12. Funnel MM, Brown TL, Childs BP, Haas LB, Hosey GM, Jensen B et al. National standards for diabetes selfmanagement education. Diabetes Care. 2012; 35(1): S101S108.

13. Health literacy: report of the Council on Scientific Affairs. Ad Hoc Committee on Health Literacy for the Council on Scientific Affairs, American Medical Association. Journal of the American Medical Association. 1999; 281: 552-557.

14. Rafique G, Azam SI, White F. Diabetes knowledge, beliefs and practices among people with diabetes attending a university hospital in Karachi, Pakistan. Eastern Mediterranean Health Journal. 2006; 12: 590-598.

15. Perera DP, De Silva RE, Perera WL. Knowledge of diabetes among type 2 diabetes patients attending a primary health care clinic in Sri Lanka. Eastern Mediterranean Health Journal. 2013; 19(7): 644-648.

16. Schillinger D, Piette J, Wang F, Osmand D, Daher C, Sullivan GD et al. Association of health literacy with diabetes outcomes. Journal of the American Medical Association. 2002, 288: 475-482.

17. Public awareness of diabetes mellitus in Singapore. Singapore Medical Journal. 2002; 43(3): 128-134.

18. Shah VN, Kamdar PK, Shah N. Assessing the knowledge, attitudes and practice of type 2 diabetes among patients of Saurashtra region, Gujarat. International Journal of Diabetes in Developing Countries. 2009, 29: $118-122$. 